\title{
Gypsum Expanded Clay Concrete for External Walls
}

\author{
Alexander Panchenko, ${ }^{1, *}$ and Nikita Kozlov ${ }^{2}$ \\ ${ }^{1}$ Moscow State University of Civil Engineering, Yaroslavskoe shosse, 26, Moscow, 129337, Russia \\ 2“"Promressurs" Co. Ltd. Moscow, Russia
}

\begin{abstract}
The technology of multicomponent water-proof gypsum binder and gypsum expanded clay concrete with water resistance increased by 1.8-2.2 times comparing to the initial gypsum, and with a softening coefficient of $0.85-0.91$, is developed and patented. The binder contains a complex mineral additive including a waste product, carbide silt, and biosilica. The use of the carbide silt (waste product from the acetylene production) together with the biosilica as the WPB components provides for both the engineering-and-economic efficiency and the ecological one. The energy consumption of the WPB production is considerably lower than that of other widely used binding agents based on the Portland cement due to the reduction of the electric power consumption by 2.5 to 3 times and that of the fuel by 3 to 3.5 times. Gypsum expanded clay concrete prepared on the basis of this binder has water resistance, freeze-thaw resistance and creep measure allowing to use it as a wall material for manufacturing wall blocks or for erecting monolithic buildings.
\end{abstract}

\section{Introduction}

In recent years, the demand for low-rise residential buildings has been growing significantly in the modern residential construction both in Russia and abroad. Among the existing technologies of erecting low-rise buildings, the most popular ones are brick buildings, lightweight concrete blocks, less often, monolithic buildings made of lightweight aerated concretes, as well as wood. The use of concretes prepared on the basis of Portland cement or brick for erecting residential buildings is controversial from the viewpoint of technical and economic efficiency. Each of these materials has its advantages and disadvantages. The energy consumption of $1 \mathrm{~m}^{2}$ of an external wall of a residential building of those materials is almost the same, brick wall $35 \ldots . .45 \mathrm{kgoe} / \mathrm{m}^{2}$ and expanded clay concrete $35 \ldots 40 \mathrm{kgoe} / \mathrm{m}^{2}$.

It is possible to realize the advantages and, simultaneously, reduce the influence or even eliminate the disadvantages of each of these materials and technologies of building through

\footnotetext{
Corresponding author: alex250354@gmail.com
} 
the use of lightweight concretes on the basis of gypsum binders. An important advantage of such concretes is their low energy consumption and relative easiness of production of gypsum binders, as well as high speed of curing of concrete on the basis thereof. The energy consumption $1 \mathrm{~m}^{2}$ of an external wall of gypsum expanded clay concrete is $14 \ldots 18 \mathrm{kgoe} / \mathrm{m}^{2}$, and Portland cement based concrete $32 . .37 \mathrm{kgoe} / \mathrm{m}^{2}$ [1]. Of course, the first option has clear advantages.

\section{Analytical procedure}

For the wall materials, it is very important that the density of gypsum stone is almost 1.5 times lower than the density of cement, which allows to reduce the required thickness of enclosing structures and the weight of the building. Using of pigments for preparing gypsum expanded clay concrete allows to diversify the facades of buildings. High speed of maturing of gypsum concrete speeds up the manufacturing of products or erection of monolithic structures and, therefore, increases considerably the reusability of forms or formworks. It is also important to mention the abundance of gypsum stone fields, high fire resistance, sound-insulation capacity and environmental friendliness of gypsum products $[2$, 3].

Beside the indicated advantages, building gypsum and concretes on the basis thereof have low water and freeze-thaw resistance $[2,3]$. A material is considered water resistant, if its softening coefficient is $0.75-0.8$ or more, but for the gypsum based concretes, as known, it is only $0.4-0.5[4,5]$. The gypsum concrete freeze-thaw resistance grade does not exceed F15-F25. Of particular note is the high creep of gypsum dihydrate and concretes on the basis thereof, which is three or more times higher than the creep of lightweight cement concretes, leading to unacceptable deformations in the paces of support of floor beams, discharging pieces, stair flights, etc. and, consequently, intensive crack formation on a wall structure.

At present, an increase in the operational serviceability of gypsum concretes is provided through the use of mixed gypsum binders containing, beside hemihydrate gypsum, Portland cement, active pozzolanic material and other mineral substances [3-5]. As it will be shown below, it is possible to quite efficiently ensure the required serviceability of wall products and structures of gypsum expanded clay concrete using a waste product, carbide silt, in combination with high performance hydraulic additive, biosilica, as components of mixed gypsum binder.

The use of carbide silt obtained in the form of waste when producing acetylene in acetylene generators through degradation of calcium carbide $\mathrm{CaC}_{2}$ with water by the following reaction: $\mathrm{CaC}_{2}+\mathrm{H}_{2} \mathrm{O}=\mathrm{Ca}(\mathrm{OH})_{2} \downarrow+\mathrm{C}_{2} \mathrm{H}_{2}$, not only gives an opportunity to obtain an efficient multicomponent water-resistant gypsum binder (WPB) for enclosing structures, but to also provide an appreciable environmental effect. Carbide silt is a largetonnage waste. In theory, in the process of degradation of $1 \mathrm{~kg}$ of chemically clean calcium carbide, $0.562 \mathrm{~kg}$ of water are required, which will lead to production of $0.406 \mathrm{~kg}$ of acetylene and $1.156 \mathrm{~kg}$ of carbide silt. In 2016, 400 thousand tons of acetylene were produced in the Russian Federation; in addition, about 1 million 140 thousand tons of carbide silt were produced. In terms of chemical composition, it consists of $92-95 \%$ active $\mathrm{Ca}(\mathrm{OH})_{2}$.

\section{Experimental procedure}

In the course of experiment, WPB carbide silt was prepared using carbide silt from five different acetylene stations. Chemical analysis of different lots of carbide silt showed that 
their chemical composition does not depend on the place of production. The humidity of the paste produced from carbide silt and water will change to a certain extent. Therefore, there is no need for frequent adjustment of the amount of carbide silt for the preparation of the additive, but the humidity of the paste must be taken into consideration.

Biosilica is a finely dispersed silicon dioxide of biogenic origin obtained after heat treatment and special combined activation of natural diatomite. Hydraulic activity of biosilica reaches $395 \mathrm{mg} / \mathrm{g}$ which exceeds considerably the activity of man-made mineral additives, such as microsilica, high activity fly-ash, etc. [6-8]. Biosilica has a constant chemical composition and activity, which allows to correct the WPB composition, being guided only by the gypsum certificate data.

Based on the results of the authors' research carried out in 2014-2017 at the Department of Technology of Binders and Concretes of Moscow State University of Civil Engineering, the technology of preparation of water-resistant binding multicomponent gypsum with water resistance increased by 1.8-2.2 times comparing to the initial gypsum, and with the softening coefficient within $0.85-0.91[9,10]$ as developed. The use of a complex additive provides a denser structure through the early formation of low-basic calcium silicate hydrate during both moist and dry curing.

\section{Experimental results and discussion}

Since for producing gypsum expanded clay concretes of different strength classes the use the initial gypsum of different grades is required, the experimental research was carried out for the purpose of determining the optimum proportion of carbide silt and biosilica, as well as the amount of silt and silica additive for different grades of the initial gypsum. "Optimum" means the proportion providing the highest softening coefficient $\mathrm{C}_{\mathrm{s}}$ of cured binder samples. The value of proportion of $\mathrm{SiO}_{2}: \mathrm{Ca}(\mathrm{OH})_{2}$, where, in theory, full reaction of components occurs, can be obtained by stoichiometric calculation and is equal to $1: 1.6 \ldots 1.7$. For experimental proof and clarification of this provision, a research of water resistance of WPB prepared on the basis of hemihydrate gypsum of different grades and manufacturers was carried out. In the course of the experiment, samples matured in normal conditions for 28 days were prepared and tested.

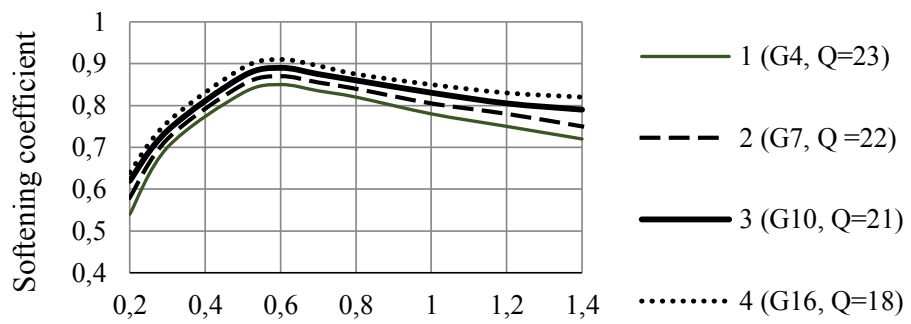

Proportion of $\mathrm{SiO}_{2} / \mathrm{Ca}(\mathrm{OH})_{2}$ in additive

Fig. 1. Dependence of the softening coefficient of WPB on the proportion of $\mathrm{SiO}_{2} / \mathrm{Ca}(\mathrm{OH})_{2}$ within silt and silica additive for different grades of initial gypsum ( $Q$ is the quality of the additive added to the binder).

The results are given on Figure 1. It is established that the optimum proportion of biosilica to carbide silt (in WPB) is $0.55-0.65$ and practically does not change in case of use of hemihydrate gypsum of different grades within the range of G4 to G16 as initial gypsum. Moreover, the amount of silt and silica additive providing the maximum value of softening coefficient somewhat decreases (from 23 to 18 percent) with an increase in the 
grade of the initial gypsum from G4 to G16. The test was carried out with a proportion of $\mathrm{SiO}_{2}: \mathrm{Ca}(\mathrm{OH})_{2}$ equal to 0.6 regardless of the gypsum grade.

As well-known [2,9], decrease in the proportion between open and general porosity of matured binder $\left(\mathrm{P}_{\mathrm{o}} / \mathrm{P}\right)$ should be sought in order to provide weather resistance of the wall material. An increase in the weather and freeze resistance of WPB based wall material can be forecasted through analysis of the data on the determination of opened porosity and its relation to general porosity. The volume and number of open pores of matured WPB will decrease significantly in relation to hemihydrate gypsum. Adding silt and silica additive to initial gypsum of grade $\mathrm{G} 5$ the $\mathrm{P}_{\mathrm{o}} / \mathrm{P}$ proportion will decrease from 0.53 to 0.27 , that is almost twice, and in case of using gypsum G10 as the initial gypsum, $\mathrm{P}_{\mathrm{o}} / \mathrm{P}$ will decrease by more than $40 \%$.

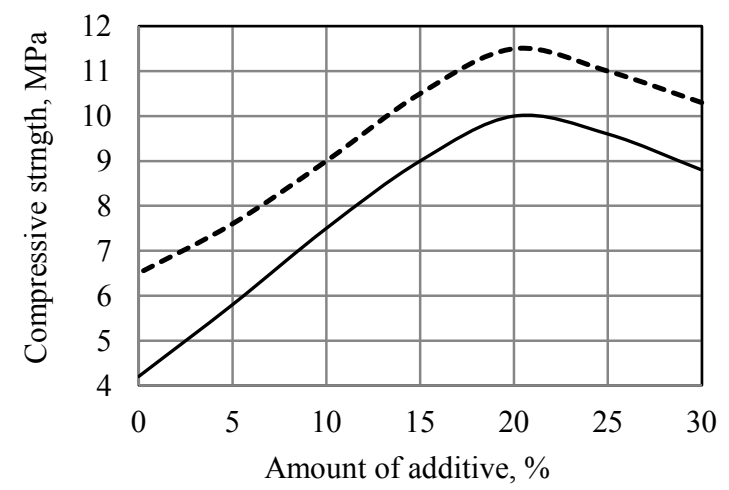

----- oven-dried sample

water-saturated samples

Fig. 2. Dependence of compressive strength of gypsum expanded clay concrete on the amount of silt and silica additive added to WPB

Research on the influence of the amount of silt and silica additive added to WPB on the water resistance of expanded clay concretes was carried out using $10 \times 10 \times 10 \mathrm{~cm}$ test cubes. Gypsum expanded clay concrete prepared using G5 construction gypsum was used as a reference. The curing conditions for all samples were the same: natural dry, during 14 days. Figure 2 shows that adding silt and silica additive up to the optimum value, the strength in water-saturated state will increase by 1.8...2.0 times, and then it will start to decrease. In dried state, the strength of the samples will increase as well, although to a lesser extent, by 1.3...1.5 times. The influence of the silt and silica additive on the main properties, and, first of all, on the gypsum binder water resistance and strength is expounded in [6].

The start of setting within 45-60 minutes must be ensured for preparing the concrete mix both in factory and building conditions and for its delivery to the place of pouring and consolidating. This time of start of setting was provided using sodium tetraborate (STB) in the amount of $0.45 \ldots . .5 \%$ of the WPB weight. The experiment results have shown that such amount of STB does not decrease, but even somewhat increases (up to $10-15 \%$ ) the compressive strength of WPB based concretes.

Expanded clay gravel filler, as well-known, somewhat increases the water demand of concrete mix; however, in the process of subsequent curing, an important role will be played by the accumulator of moisture gradually entering the gypsum stone being cured from the expanded clay grains during a long period of time, thereby contributing to the continuation of the process of hydration of silt and silica additive.

Gypsum binders adhere weakly to the filler during curing; this will have a negative impact on the strength of gypsum concretes. The use of expanded clay with porous surface 
contributes to increased strength of adherence of gypsum stone with the filler and increased strength of expanded clay concrete. This is explained by both mechanical constraint of mineral glue inside the filler pores and by chemical interaction of contacting phases. Amorphous $\mathrm{SiO}_{2}$ contained in burnt expanded clay gravel interacts chemically with lime, which is the main component of silt and silica additive. This causes low-basic hydrated calcium silicate poorly soluble in water to produce on the contact surface, consolidating the contact layer.

The technology of preparation of concrete mix somewhat changes based on the type of carbide silt in the form of paste or carbide silt dried until the constant weight. The sequence of preparation of concrete mix includes the following:

- gravimetric batching of the materials used;

- in case of use of carbide silt in the form of dough or paste as components of silt and silica additive, previous mixing of the dough (paste) with mixing water or part of mixing water is recommended, then superplasticizer, biosilica, filler and the rest of mixing water together with setting retarder are added. After mixing during 1-2 minutes, gypsum is added to the mix and final preparation of concrete mix is performed during 3-4 minutes;

- when using carbide silt dried until the constant weight, the components of silt and silica additive are added together with the filler and set with water together with setting retarder and superplasticizer. After mixing during 1-2 minutes, gypsum is added to the mix, and during 3-4 minutes of mixing, the mix is ready for use.

A few options of concrete curing are possible after the mix has been poured into the form or formwork and consolidated. Studying of strength development of WPB based expanded clay concrete in different curing conditions allow to make a conclusion on the possibility to use both steam curing and normal or naturally dry curing conditions. Steam curing of concrete during 10-16 hours is the fastest and effective enough in terms of increase in water resistance. Curing of WPB samples in normal conditions during 14 days will allow to obtain a softening coefficient of up to 0.91 and higher strength of samples in water-saturated condition. Curing of samples in naturally dry conditions will allow to achieve a little lower value of softening coefficient, but in this case, its value will be no less than 0.85 . Thus, any of the aforementioned methods can be used for obtaining water resistant wall blocks or erecting monolithic enclosing structures. Moreover, formwork removal of a structure or removal of products from the forms can be performed in 34 hours after pouring and consolidating of concrete mix.

Softening coefficient of materials for external enclosing structures must be no less than 0.6-0.7, the strength class no less than B2.5-B3.5, and the average density in dry state in accordance with the requirements of SP 70.13330.2012. Load-bearing and enclosing structures up to D 1400. The freeze-thaw resistance grade must not be lower than F25-F35 (SP 15.13330.2012. Masonry and reinforced masonry structures) based on the region. Normally, the coefficient of thermal conductivity of material for external walls must be within $0.16 \ldots 0.45 \mathrm{~W} / \mathrm{m}^{\circ}{ }^{\circ} \mathrm{C}$. The thermal conductivity of WPB based expanded clay concrete was determined using $4 \times 20 \times 20 \mathrm{~cm}$ samples. Two compositions of gypsum expanded clay concrete with the density of 1190 and $1280 \mathrm{~kg} / \mathrm{m}^{3}$ in dry condition were tested. As the result of the measurement, the coefficient of thermal conductivity $\lambda$ was 0.265 and $0.315 \mathrm{~W} / \mathrm{m} \cdot{ }^{\circ} \mathrm{C}$ respectively. Expanded clay concrete based on Portland cement with the density of $1200 \mathrm{~kg} / \mathrm{m}^{3}$ has the thermal conductivity coefficient of about $0,32 \mathrm{~W} / \mathrm{m} \cdot{ }^{\circ} \mathrm{C}$.

Cycling freezing-thawing resistance was studied with the use of complex testing chamber. As the result, the WPB based expanded clay concrete withstood 125 freezingthawing cycles, which exceeds considerably the freeze-thaw resistance applied to wall materials (Figure 3a). 

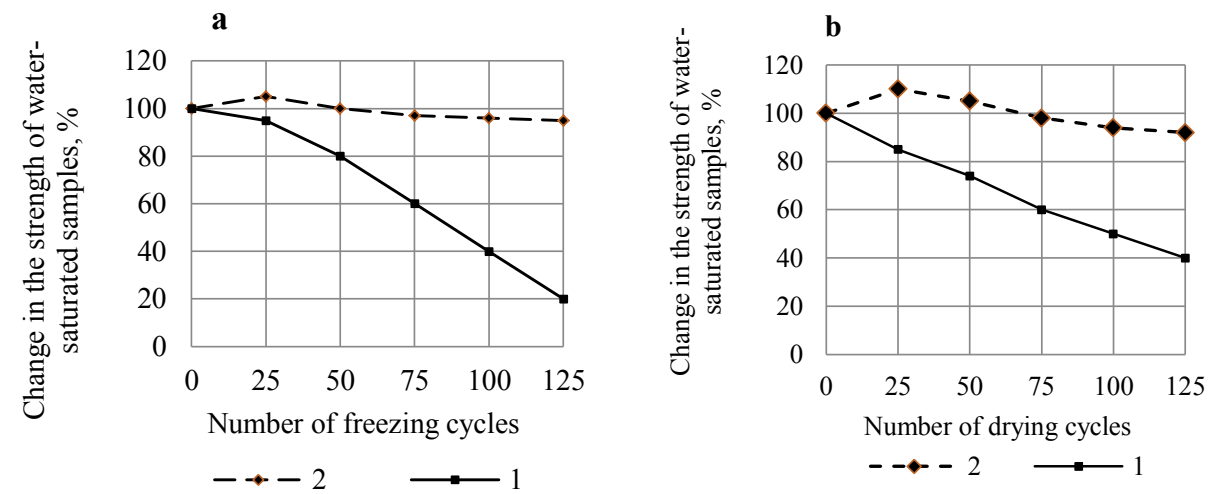

Fig. 3. Strength of expanded clay concrete based on WPB (2) and gypsum (1) in the process of freezing-thawing (A) and wetting-drying (B).

Common gypsum concrete withstood only 25 cycles, that is 5 times less. Direct testing was confirmed by indirect strength control, based on the speed of ultrasonic transmission, as well as by measurement of resonance frequency, which characterize the influence of the testing on the change in the value of the dynamic modulus of elasticity

Resistance to alternate heating-cooling and wetting-drying was studied by the methodology where the material dried up to its constant weight at the temperature of $55^{\circ} \mathrm{C}$ was saturated by water during 18 hours after cooling (4 hours). Then the cycle was repeated. It was established that WPB based concrete loses only $5 \%$ of strength, and normal gypsum concrete up to $50 \%$ (Figure $3 \mathrm{~b}$ ) after 90 cycles.

A complex appraisal of physical and mechanical properties of WPB based expanded clay concrete (Table 1) was carried out comparing to gypsum (P) based analog concretes, gypsum cement pozzolan binder (PCPB) and Portland cement (PC). The research was carried out with the use of concretes of the same class. Based on the result given in table 1 we can conclude that in term of main physical and mechanical characteristics WPB based expanded clay concrete is practically not less than PC based expanded clay concrete, with few exceptions. In addition, as it was shown above, its thermal conductivity is 1.3 times less, which, of course, decreases the required thickness of the external enclosing structure and decreases its weight with other conditions being equal.

Table 1. Physical and mechanical characteristics of expanded clay concretes of class B10

\begin{tabular}{|l|c|c|c|c|}
\hline \multirow{2}{*}{ Properties } & \multicolumn{4}{|c|}{ Binders for expanded clay concrete } \\
\cline { 2 - 5 } & WPB & Gypsum & PC & PCPB \\
\hline $\begin{array}{l}\text { Compressive strength in water- } \\
\text { saturated condition, MPa }\end{array}$ & 9.6 & 5.6 & 10.2 & 8.8 \\
\hline Softening coefficient, $\mathrm{C}_{\mathrm{s}}$ & 0.87 & 0.45 & 0.92 & 0.7 \\
\hline $\begin{array}{l}\text { Relative creep deformation, } \times \\
10^{-5}, \mathrm{MPa}^{-1}\end{array}$ & 14.0 & 29.8 & 13.5 & 19.0 \\
\hline Freeze-thaw resistance, cycles, & 125 & 25 & 125 & 50 \\
\hline
\end{tabular}




\begin{tabular}{|l|r|r|r|r|}
\hline Modulus of elasticity, MPa & 19,100 & 8,300 & 22,000 & 17,500 \\
\hline
\end{tabular}

It should be specifically noted that creep deformations of WPB based expanded clay concrete is 2.2 times lower that expanded clay concrete on the basis of building gypsum and are at the level of cement concretes of equal class. It is very important for gypsum binders, together with water resistance and freeze-thaw resistance, provide the required creep value of wall material not exceeding the critical one, since it is high creep of gypsum concrete that frequently does not allow to provide the required serviceability of wall structures and building as a whole.

\section{Conclusions}

It is possible to increase the required serviceability of wall products and structures of gypsum expanded clay concrete using a carbide silt, in combination with high biosilica, as components of mixed gypsum binder.

The main physical and mechanical characteristics WPB based expanded clay concrete are not less than PC based expanded clay concrete, that allows to use it as a wall material for manufacturing wall blocks or for erecting monolithic buildings.

The energy consumption of the WPB production and expanded clay concrete based on it is considerably lower than that of Portland cement due to the reduction of the electric power consumption by 2.5 to 3 times as well as fuel by 3 to 3.5 times.

The use of carbide silt obtained in the form of waste not only gives an opportunity to obtain an efficient water-resistant gypsum binder for enclosing structures, but also provides an appreciable environmental effect.

\section{References}

1. Yu. M. Bazhenov, Technology of concrete, 528 (2011)

2. A.V. Ferronskaya, V. F. Korovyakov, I. M. Baranov, A. F. Buryanov, Yu. G. Losev, V.V. Poplavsky, A.V. Shishin, Gypsum in low-rise construction, 240 (2006)

3. V.F. Korovyakov, Building materials, equipment, technologies of 21 st century, 3, 8 (2005)

4. A.I. Panchenko, G.V. Nesvetaev, A.U. Nechushkyn, 12 Ibausil (Weimar), 112 (1994)

5. R.Z. Rakhimov, M. I. Khaliulin, A. R. Gayfulin, Building Materials, 7, 13-16 (2012)

6. A.P. Pustovgar, Building materials, 10, 6 (2006)

7. A.A. Plugin, A.H. Plugin, H-B. Fisher, G.N. Shabanova, 1 Weimarer Gipstagung BauhausUniversität (Weimar), 435-443 (2011)

8. M. Sanytsky, T. Kruts, T. Kropyvnytska, B. Rusyn, 14th International congress on the Chemistry of Cement (Beijing China), 365-370 (2015)

9. A. Panchenko, N. Kozlov, MATEC Web of Conferences, 86, 06001 (2016)

10. A.I. Panchenko and etc. Patent 2562621 Russian Federation, 3 (2015) 